\title{
Modeling Multi-generation Innovation Adoption based on Conjoint effect of Awareness Process
}

\author{
Mohini Agarwal $^{1}$, Deepti Aggrawal ${ }^{2 *}$, Adarsh Anand ${ }^{1 \#}$, Ompal Singh ${ }^{1 !}$ \\ ${ }^{1}$ Department of Operational Research \\ ${ }^{2}$ Keshav Mahavidyalaya \\ University of Delhi, Delhi 110007, India \\ ${ }^{1}$ mohini15oct@gmail.com, deepti.aggrawal@gmail.com, \#adarsh.anand86@gmail.com, \\ !drompalsingh1@gmail.com \\ ${ }^{*}$ Corresponding author
}

(Received October 1, 2016; Accepted December 13, 2016)

\begin{abstract}
The prior models in the field of multi-generation diffusion modeling basically concentrated on employing effects of substitution and switching behavior. But little or no importance has been given to the manner in which information about the product is diffused in the marketplace for eventual determination of intergenerational sales. Sales generally happen when users are informed about the characteristic features of the product. Thus, the effect of information flow on adoption of the product is important for evaluating eventual sales. With the aim of inculcating awareness and adoption process as two different factors impacting the overall sales; in this paper we have developed a systematic approach to model the sales for intergenerational diffusion process. The results are verified on sales data from Semiconductor Industry DRAM shipments.
\end{abstract}

Keywords: Cross-generation shifting; Innovation-diffusion models; Intergenerational diffusion.

\section{Introduction}

Today successful firms are recognized for their innovative strategies and recurring launches in terms of new product introductions. Firms seek to adopt new product introduction strategy to gain long-term financial success and to increase demand of the products. The major work on new product sales model is based on innovation-diffusion theory (Kapur et al., 2010; Singh et al., 2012; Aggrawal et al., 2015). The topic diffusion process has been widely studied by researchers from different disciplines. Diffusion is the process through which a new idea or new product is accepted in the market (Anand et al., 2014b) whereas innovativeness defines the difference among individuals in their response to new product or ideas and is also a measure to define the earliness of an individual in adopting a product (Anand et al., 2014b). Eventually the aggregate adoption of all individual in particular time horizon determines the diffusion of a product. The diffusion theory has gained attention from the pioneering work done by F. M. Bass in1969 which is considered to be the most widely used and extended model to present date. Till now there have been extensive work to extend single generation model to account for more realistic scenarios that persist in the market. Some researchers have extended the first purchase sales model to include marketing mix variable (Mahajan and Wind, 1985; Kalish and Sen, 1986; Bass et al., 1994) Stages in the adoption process (e.g., Kalish, 1985; Midgley, 1976), supply restrictions (e.g., Ho et al., 2002; Jain et al., 1991), repeat and replacement purchases (Lilien et al., 1981; Wind and Sharma, 1983), Retailer adoption (e.g., Bronnenberg and Mahajan, 2001) and spatial diffusion (Garber et al., 2004); processes for interpersonal communication (e.g., cellular automata, Garber et al., 2004; Goldenberg et al., 2002); cross-market communication (Goldenberg et al., 2002). 
International Journal of Mathematical, Engineering and Management Sciences

Vol. 2, No. 2, 74-84, 2017

https://dx.doi.org/10.33889/IJMEMS.2017.2.2-008

The recent policy adopted by companies is to keep rolling out new versions one after another, with newer versions being acquainted with some additional functionality. Generally firms do not deliver their complete product in one go but keep launching new version frequently to maintain their competitive edge in the market. Majority of examples can be quoted such as: family of Apple's iPod and iPhone; also family of Microsoft Windows and Offices and many more (Jiang and Jain, 2012; Aggrawal et al., 2015). Bringing successive generations help the firms in improving the quality of the product in latter development cycles. It also helps in attaining quicker returns on their investments and the impact of market uncertainties. Successful products in the market are generally substituted by newer generations with advanced features and functionalities which can create new markets and can lead to increased sales. First- purchase sales models were not capable in explaining the diffusion process for multi-generational product. Thus, there was the towering need for predicting the sales behavior for multi-generational products. Several models starting with Norton and Bass model (1987) for predicting how multiple generations of a product compete have been proposed. Following Norton and Bass (1987), other researchers developed extensions and variations to the Norton and Bass model to examine how the entry of new generation cannibalizes the sales of existing generations in the market (Mahajan and Muller, 1996; Islam and Meade, 1997; Meade and Islam, 2006, Jiang, 2010).

Understanding of "what are customers' attitudes toward the product or service?" is a key concern for marketers. For knowing the perception of individuals, firms need to advertise and promote their product which may generate a group of prospective buyers who with passage of time may adopt the product. Therefore, it is wise to articulate that advertising and promotion may act as integral part of our social and economic systems. Small retailers to large multi-national companies are increasingly getting dependent on advertising and promotion to help them market products and services. On the other hand, consumers are also dependent on promotion and other sources for information, which they can use in making purchase decision. Thus, the need for means of advertisement cannot be ignored in recent times for building thought process of individuals. Working on similar grounds of, increased demand of studying the impact of awareness process on adoption process; researchers have worked on extending single stage models to multi- stage innovation diffusion models (Van den Bulte and Lilien, 2007; De. Bruyn and Lilien, 2008; Anand et al., 2014a). Considering this very mind set, we have come with a proposal to study the impact of multi-stage nature of adoption on inter-generational sales of product. Empirical verifications of previous studies show that multi-generation diffusion models are applicable not only to technological products such as IBM mainframe computers and mobile phones, but also to non-technological products such as milk containers (Speece and MacLachlan, 1995). But this study is only concentrated on studying the impact of high technology product.

Massive amount of work has been done in the field of diffusion theory accounting from single generation of a product (Bass, 1969) to its successive generations (Norton and Bass, 1987). Also, from single stage to multi-stage nature of adoption process based on theoretical structure given by Rogers (1962). Some of the glimpses are described to smoothen the understanding of the present work. The remainder of the paper is organized as follows. In Section 2, we briefly review literature of multi-generation. The proposed model is presented in Section 3. Empirical analysis of proposed is reported in Section 4. Finally we discuss the managerial implications of this study and conclusion in Section 5 and 6 respectively. Further in Section 7 comprises of Acknowledgement followed by references at last. 
International Journal of Mathematical, Engineering and Management Sciences

Vol. 2, No. 2, 74-84, 2017

https://dx.doi.org/10.33889/IJMEMS.2017.2.2-008

\section{Brief Background}

Research for modeling the sales of multi-generation is abundant still more work is in pipeline. The first ever model of multi-generations of a product was proposed in the year 1987. Norton and Bass (1987) as being the most parsimonious model in the field of successive generations, acknowledged the existence of substitution and skippers but do not differentiate them. Even though Norton and Bass model has certain limitations, still it remains the most applied and extended model in the field of multi-generation till date. Speece and MacLachlan (1995) tested and applied the Norton and Bass model (1987) for forecasting the sales of successive generation of packaging technology of milk containers. Mahajan and Muller (1996) extended the Norton and Bass model (1987) to account for more variability in terms of skipping done by adopters, i.e. an adopter of the first generation could replace it with third generation, etc. They applied their model to sales of high-technology product i.e. IBM Mainframe computers. In the year 2010, Jiang extended the Norton and Bass model (1987) that differentiates the different types of adoption. Kapur et al. (2010), proposed a multigenerational diffusion model considering the impact of repeat-adoption-substitution diffusion in their model. Based on similar lines Jiang and Jain (2012) proposed Generalized Norton and Bass model which uses exactly the same set parameters as Norton and Bass model. A study to examine the number of product sold and number of product in use of two different generations is recently proposed by Aggrawal et al. (2015).

In this paper, we propose an inter-generational sales model under the joint impact of two different processes namely awareness process and adoption process. Using a very realistic saying that, "Sales of the product can happen only after prospective buyers have information about the characteristic features of the product" (Anand et al., 2014a). Awareness process can be defined as informing the individuals by means of which they may form an opinion (which might result into adoption of the product) whereas in adoption process, informed individuals with positive perception towards the product may turn up to be an adopter.

\section{Modeling Framework}

\subsection{Assumptions}

(i) Intergenerational shifting is allowed and Substitution and Switching are together considered as shifters.

(ii) Repeat purchase in the same generation is not allowed.

(iii) Adoption process is dependent on awareness process flowing in the market place.

(iv) Informed individuals having only positive perception (who actually turn up becoming adopters) are considered.

In line with all the aforesaid assumption and using the concept proposed by Anand et al. (2014a) where a process can be understood using the joint distribution of the two involved processes (awareness and then adoption in our case); in this article, we propose a framework that accounts for shift arising from one generation to successive generations and the role of informed individuals to adopter of the product. Considering substitution and switching as shifting (shifters), we assumed that $2^{\text {nd }}$ generation was introduced at time point ${ }^{\prime} \tau_{2}{ }^{\prime}$. The simplified equations are:

$$
\begin{aligned}
& N_{1}(t)=m_{1} \cdot\left(F_{1} \otimes G_{1}\right)(t)-\left(m_{1} \cdot\left(F_{1} \otimes G_{1}\right)(t)\right) \cdot\left(F_{2} \otimes G_{2}\right)\left(t-\tau_{2}\right) \\
& N_{2}(t)=m_{2} \cdot\left(F_{2} \otimes G_{2}\right)\left(t-\tau_{2}\right)+\left(m_{1} \cdot\left(F_{1} \otimes G_{1}\right)(t)\right) \cdot\left(F_{2} \otimes G_{2}\right)\left(t-\tau_{2}\right)
\end{aligned}
$$


International Journal of Mathematical, Engineering and Management Sciences

Vol. 2, No. 2, 74-84, 2017

https://dx.doi.org/10.33889/IJMEMS.2017.2.2-008

where $N_{1}(t)$ and $N_{2}(t)$ represents the cumulative number of adoption for $1^{\text {st }}$ generation and $2^{\text {nd }}$ generation respectively; $m_{1}$ and $m_{2}$ are the market potential for $1^{\text {st }}$ generation and $2^{\text {nd }}$ generation respectively; also $\left(F_{1} \otimes G_{1}\right)(t)$ represents the joint distribution function for the adoption process of $1^{\text {st }}$ generation which comprises of two different distribution accounting for awareness and adoption process on similar lines $\left(F_{2} \otimes G_{2}\right)\left(t-\tau_{2}\right)$ represents the joint distribution function for the adoption process of $2^{\text {nd }}$ generation attributing to awareness and adoption process.

In equation (1), the first component represents the adopter's who are aware and would buy the same generation; had there been no second generational available in the marketplace. The second component shows the connection between awareness and adoption of the product when newer generation comes in market and thereby its reduction from the first component shows the eventual sales that have happened for G1 of the product. On similar grounds; equation (2) can be explained. The above framework can be extended for the case of $(i+1)^{\text {th }}$ generation being dependent on its predecessor generation i.e. on $i^{\text {th }}$ generation. As and when $(i+1)^{\text {th }}$ generation is introduced into the market at time ' $\tau_{(i+1)}$ ', a portion of those prospective buyers who would have adopted or have adopted $i^{t h}$ generation would shift to $(i+1)^{\text {th }}$ generation. Hence cumulative number of shifters (comprise of both switching and substitution) from $i^{\text {th }}$ generation to $(i+1)^{\text {th }}$ generation (taking care of the two stages) can be modeled as follows:

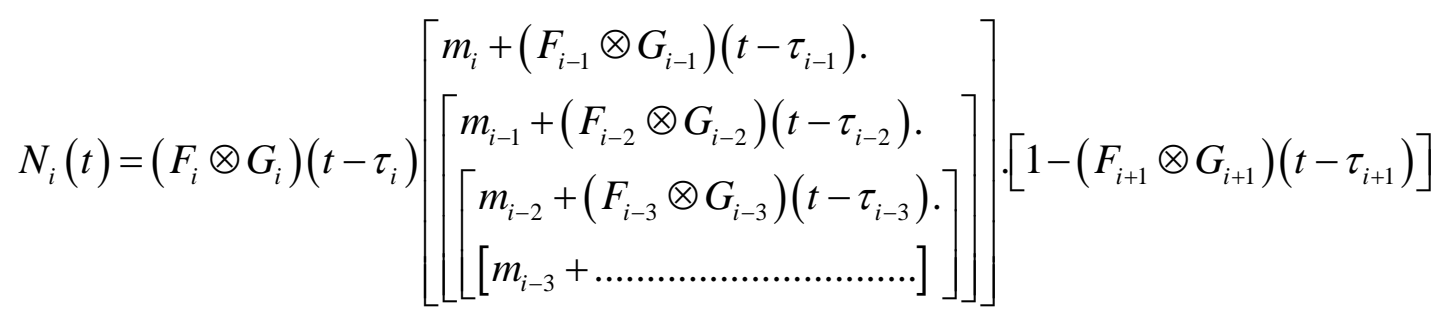

where $N_{i}(t)$ be the cumulative adoptions where $i(i=1,2 \ldots, n)$ stands for generation; $\left(F_{i} \otimes G_{i}\right)(t)$ defines the joint distribution function which is defined using Steiltjes convolution approach as used by Anand et al. (2014a).

For analytical reasons; we are now taking the case of two generation and will be presenting the sub cases accordingly:

(i) When awareness is constant and adoption is logistic in nature.

(ii) When awareness and adoption both follows exponential pattern.

(iii) When awareness is exponential and adoption behaves in logistic pattern.

(iv) When awareness and adoption both follows logistic pattern.

Above discussed cases are presented mathematically in tabular form in Table 1. On incorporating different cases in equation (1) and (2) different successive model can be obtained. 
International Journal of Mathematical, Engineering and Management Sciences

Vol. 2, No. 2, 74-84, 2017

https://dx.doi.org/10.33889/IJMEMS.2017.2.2-008

\section{Data Analysis}

The model proposed in Section 3 has been validated on data collected from a Semiconductor Industry which includes data of world-wide dynamic random access memory (DRAM) shipments of six generations 4K, 16K, 64K, 256K,1M and 4M DRAM (Victor and Ausubel, 2002) collected for a period from 1974 to 1997 . But we have used the first two generations (4K and 16K) in order to supplement our model. The parameters of proposed model were estimated using simultaneously non linear two stage least square by software package SAS (SAS/ETS User's Guide, 2004). Estimated values of diffusion parameters of the two technologies for proposed approach under different cases (as explained above) are given in Table 2.

\begin{tabular}{|c|c|c|c|}
\hline$\#$ & $F_{i}(t)$ & $G_{i}(t)$ & $\left(F_{i} \otimes G_{i}\right)(t)$ \\
\hline Case 1 & $\sim$ const & $\sim \operatorname{logistic}\left(b_{i}, \beta_{i}\right)$ & {$\left[1-\frac{\left(1+\beta_{i}\right) e^{-b_{i} t}}{1+\beta_{i} e^{-b_{i} t}}\right]$} \\
\hline Case 2 & $\sim \exp \left(b_{i}\right)$ & $\sim \exp \left(b_{i}\right)$ & {$\left[1-\left(1+b_{i} t\right) e^{-b_{i} t}\right]$} \\
\hline Case 3 & $\sim \exp \left(b_{i}\right)$ & $\sim \operatorname{logistic}\left(b_{i}, \beta_{i}\right)$ & $\left(1-e^{-b_{i} t}\right)+\left(1+\beta_{i}\right) e^{-b_{i} t} \log \left[\frac{\left(1+\beta_{i}\right) e^{-b_{i} t}}{1+\beta_{i} e^{-b_{i} t}}\right]$ \\
\hline Case 4 & $\sim \operatorname{logistic}\left(b_{i}, \beta_{i}\right)$ & $\sim \operatorname{logistic}\left(b_{i}, \beta_{i}\right)$ & {$\left[\frac{1-e^{-b_{i} t}}{1-\beta_{i}^{2} e^{-b_{i} t}}\right]+\frac{\left(1+\beta_{i}\right)^{2} e^{-b_{i} t}}{\left(1-\beta_{i}^{2} e^{-b_{i} t}\right)^{2}}\left[b_{i} t+2 \log \left[\frac{\left(1+\beta_{i}\right) e^{-b_{i} t}}{1+\beta_{i} e^{-b_{i} t}}\right]\right]$} \\
\hline
\end{tabular}

Table 1. Different forms for joint adoption function (Anand et al. (2014a))

\begin{tabular}{|l|l|l|l|l|l|l|l|}
\hline \multirow{2}{*}{ Technology } & \multirow{2}{*}{ Cases } & \multicolumn{2}{l}{ Parameters } \\
\cline { 3 - 8 } & & $m_{1}$ & $m_{2}$ & $b_{1}$ & $b_{2}$ & $\beta_{1}$ & $\beta_{2}$ \\
\hline \multirow{4}{*}{ DRAM Company } & Case 1 & 751.04 & 1332.5 & 0.5461 & 0.3653 & 35.908 & 16.552 \\
\cline { 2 - 8 } & Case 2 & 438.95 & 7745.8 & 0.323 & 0.0742 & --- & --- \\
\cline { 2 - 8 } & Case 3 & 817.21 & 1318.3 & 0.5406 & 0.372 & 14.825 & 5.3341 \\
\cline { 2 - 8 } & Case 4 & 821.17 & 1302 & 0.5759 & 0.3943 & 4.6916 & 2.1592 \\
\hline
\end{tabular}

Table 2. Parameter estimation results 
International Journal of Mathematical, Engineering and Management Sciences

Vol. 2, No. 2, 74-84, 2017

https://dx.doi.org/10.33889/IJMEMS.2017.2.2-008

\begin{tabular}{|l|c|l|l|l|l|l|}
\hline$\#$ & Generation & SSE & MSE & RMSE & R-Square & Adj R-Sq \\
\hline \multirow{2}{*}{ Case 1 } & G1 & 15914 & 1675.2 & 40.929 & 0.9004 & 0.8847 \\
\cline { 2 - 7 } & G2 & 60370 & 6354.7 & 79.716 & 0.9794 & 0.9762 \\
\hline \multirow{2}{*}{ Case 2 } & G1 & 4260.4 & 405.8 & 20.143 & 0.9733 & 0.9721 \\
\cline { 2 - 7 } & G2 & 75190 & 7914.8 & 88.965 & 0.9743 & 0.9703 \\
\hline \multirow{2}{*}{ Case 3 } & G1 & 10397 & 1094.4 & 33.082 & 0.9349 & 0.9246 \\
\cline { 2 - 7 } & G2 & 44136 & 4645.9 & 68.161 & 0.9849 & 0.9826 \\
\hline \multirow{2}{*}{ Case 4 } & G1 & 10848 & 1141.9 & 33.792 & 0.9321 & 0.9214 \\
\cline { 2 - 7 } & G2 & 39592 & 4167.5 & 64.557 & 0.9865 & 0.9844 \\
\hline
\end{tabular}

Table 3. Comparison criteria for all cases

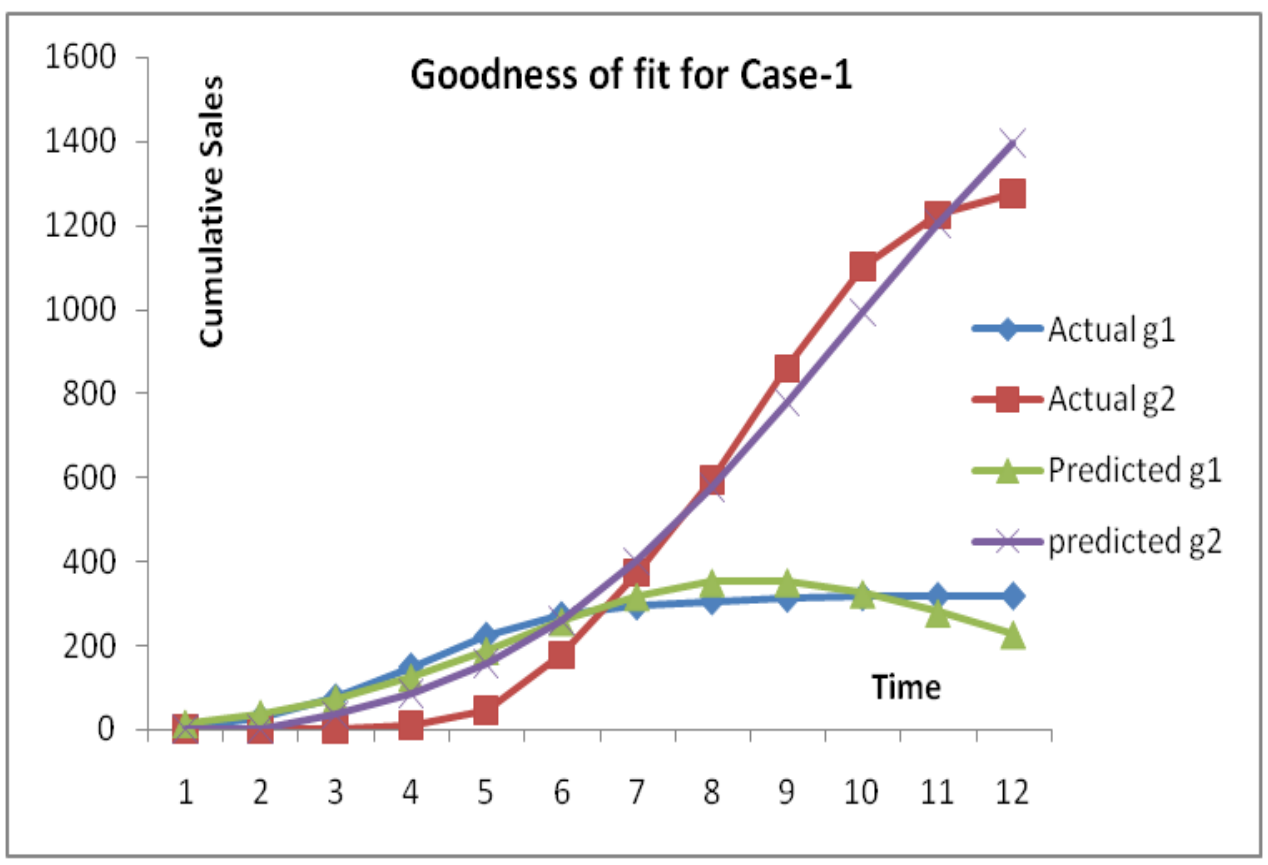

Fig. 1. Goodness of fit curve for case-1 
International Journal of Mathematical, Engineering and Management Sciences

Vol. 2, No. 2, 74-84, 2017

https://dx.doi.org/10.33889/IJMEMS.2017.2.2-008

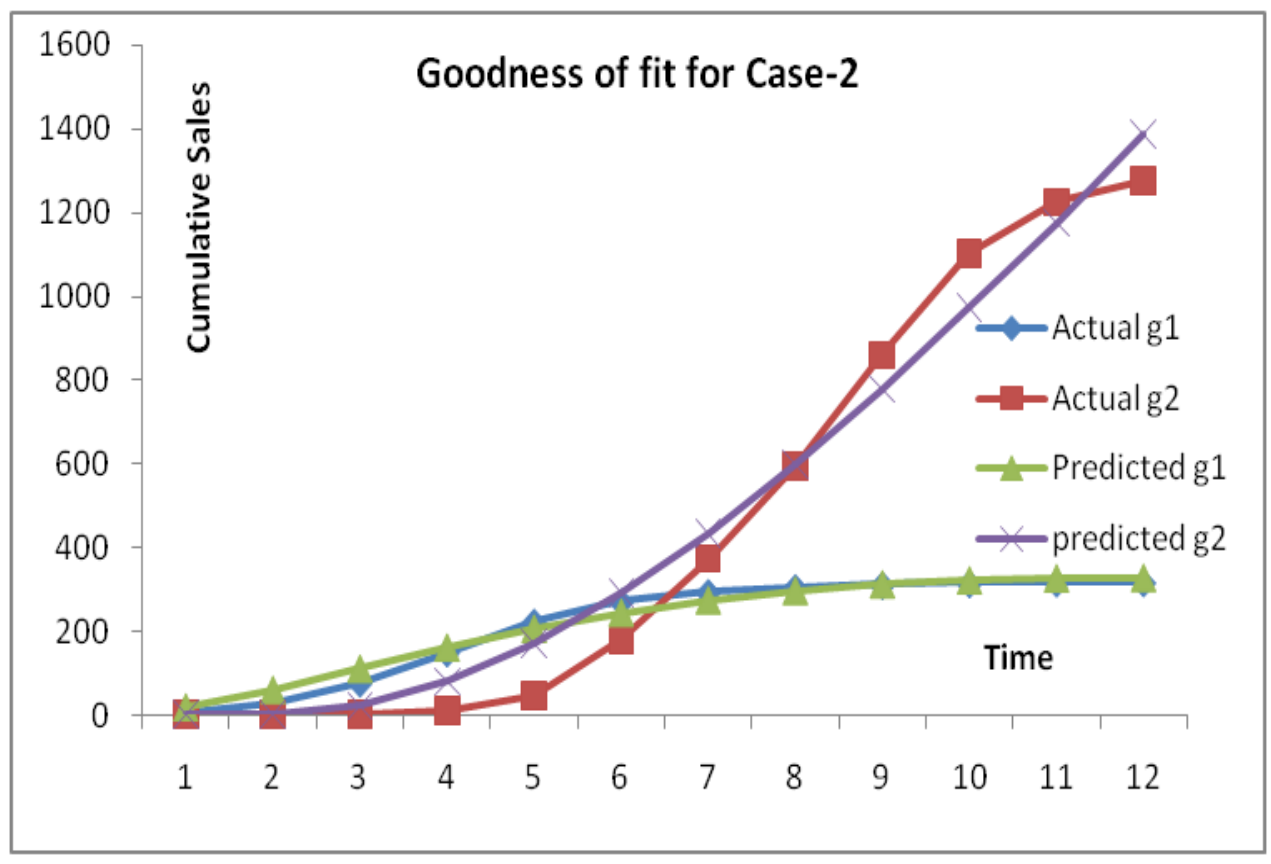

Fig. 2. Goodness of fit curve for case-2

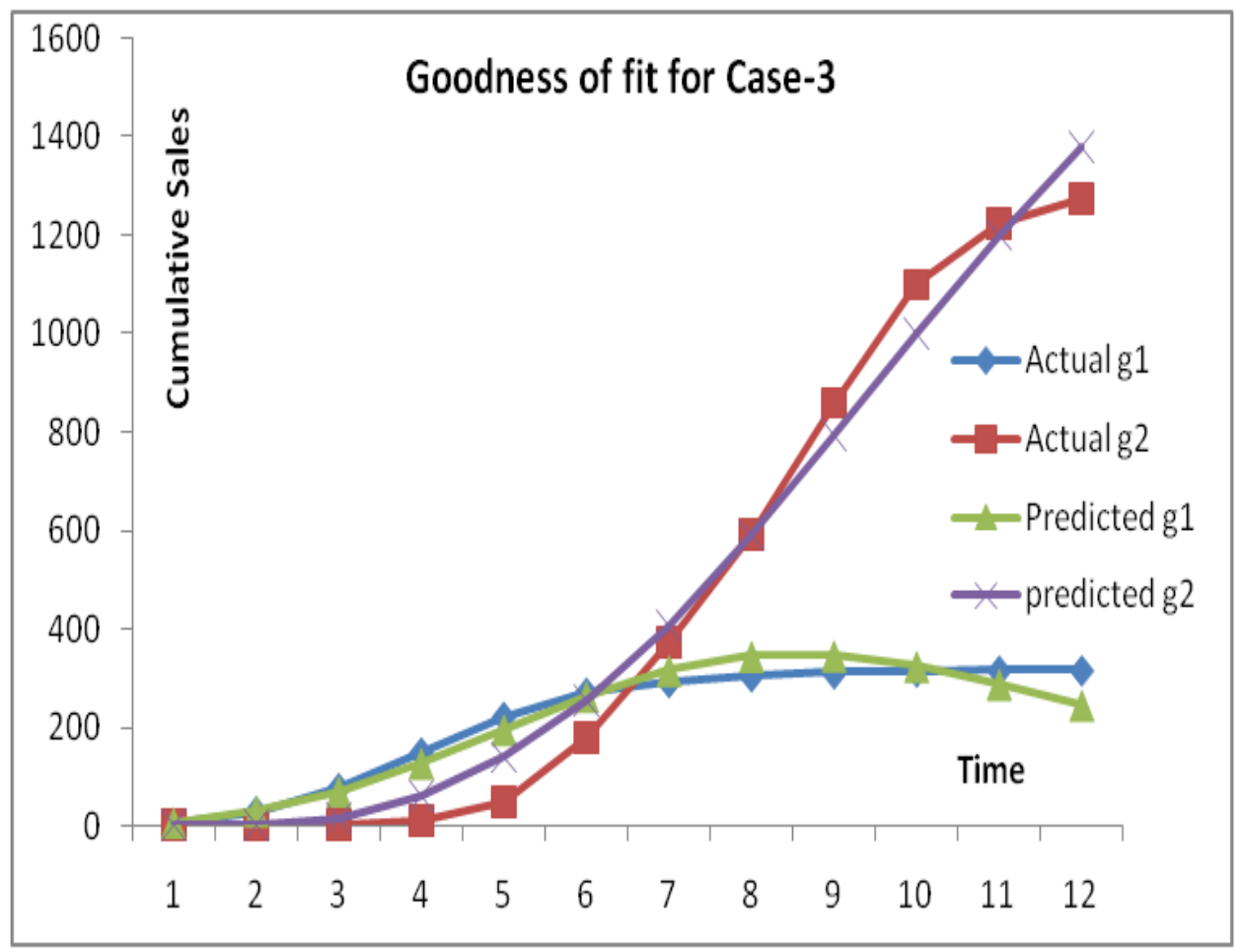

Fig. 3. Goodness of fit curve for case-3 
International Journal of Mathematical, Engineering and Management Sciences

Vol. 2, No. 2, 74-84, 2017

https://dx.doi.org/10.33889/IJMEMS.2017.2.2-008

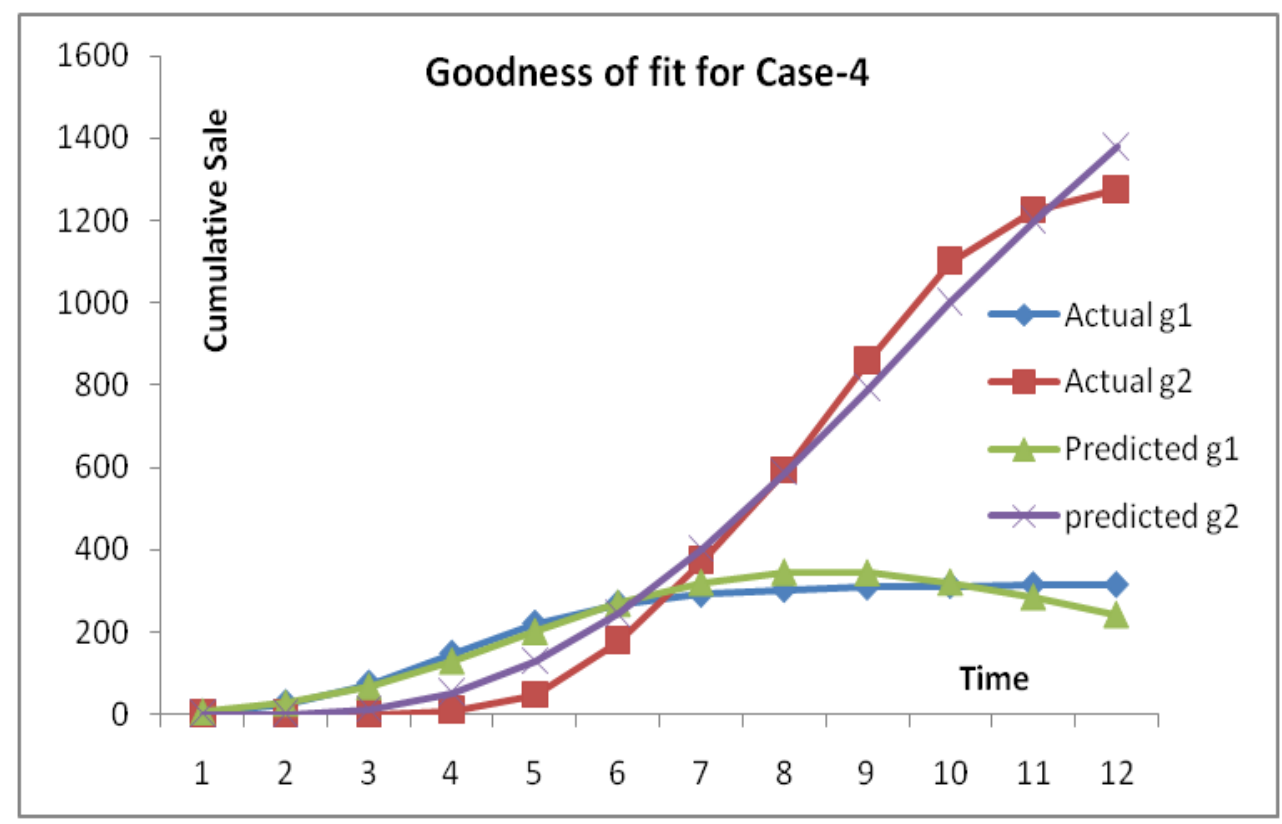

Fig. 4. Goodness of fit curve for case-4

The actual and predicted values for the DRAM data set have been illustrated via graphs (Fig. 1 to 4). Clearly the graphs presents a good and close correspondance between actual and predicted values for proposed methodology.

Table 3 and Fig. 5 shows the comparison criteria for all the cases. The MSE has minimum value of 405.8 for first generation of case-2 whereas 4167.5 as the minimum value for second generation of case-4. The values R-Square are relatively good for all cases with a minimum of 0.9004 for first generation (g1) and 0.9743 for second generation (g2) corresponding to case-1 and 2 respectively. Similar is the case of other comparison attributes. Thus it is wise to say that the proposed modeling framework shows good validation results. On examining the above table; it has been found that the case-1 i.e. when awareness is constant in the market and adoption is happening is logistic manner; the results so obtained is same as given by Norton and Bass in 1987. From this we can analyze and confirm that the model developed by Norton and Bass does not actually consider the behavior of information available about the product in the market (as can be seen from the results obtained from case-1). On scrutinizing the obtained results, it further becomes clear that the pattern in which the awareness prevails in the market does not impact the sales behavior of the product (as obtained in case - 2, 3, 4) and that is why case-1 (which is nothing but Norton and Bass model (1987) that assume constant flow of information/ constant awareness) is overpowered by all other scenarios in which the awareness flow does follow some pattern. 


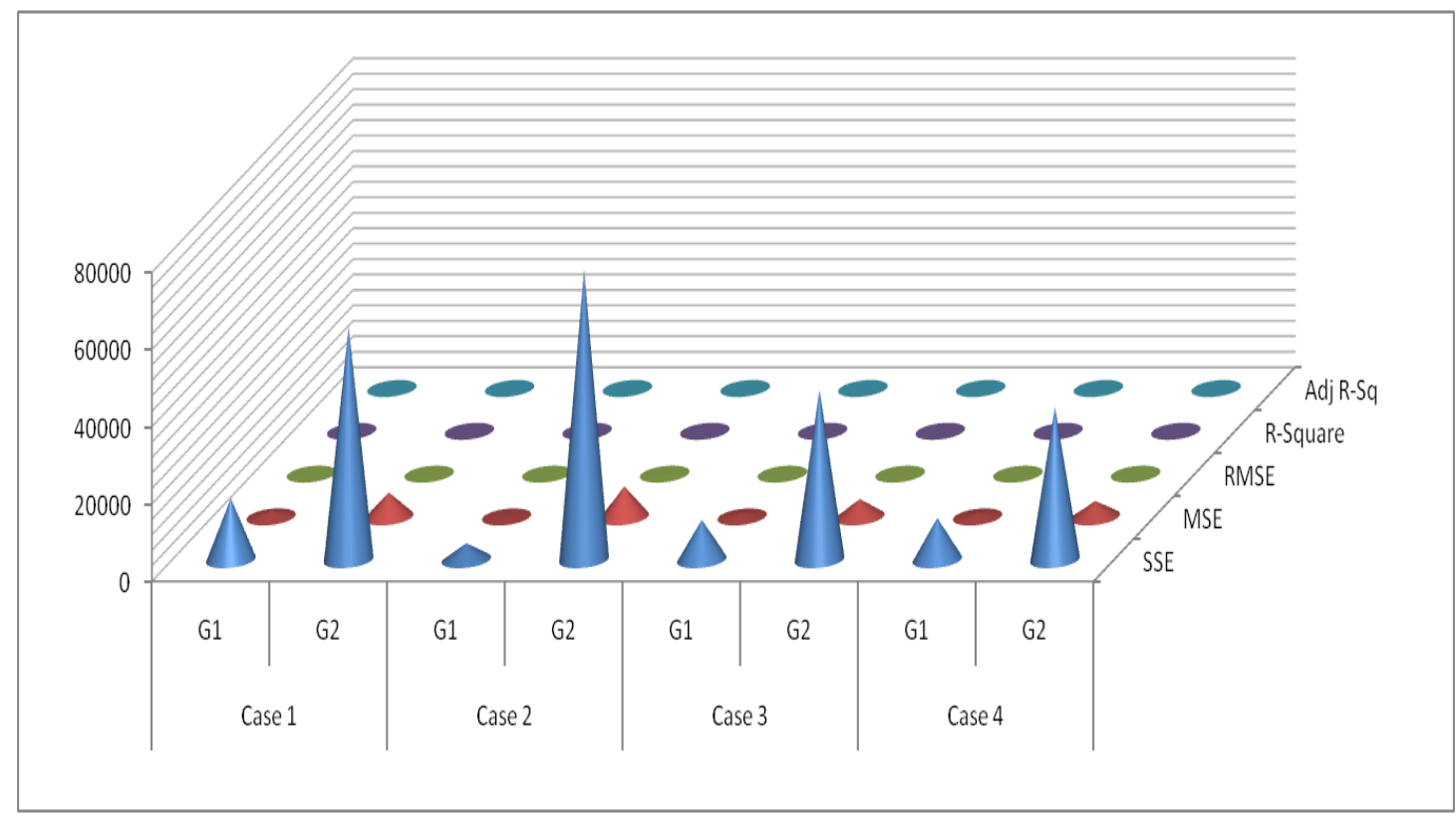

Fig. 5. Comparison criterions for all cases

\section{Managerial Implication}

Criticality associated with the launch of multiple versions of a product is something, which cannot be ignored by the firms. Managing the recurrent generation in the market, how the coming of a newer generation impact sales of existing generation and how people after being informed about available generations make their opinion about the purchase of either of them or both; these are some questions which are needed to be answered. Some of the existing multi generation models had a few capabilities to answer them. Knowing the impact of how the penetration of information among prospective buyers shapes the sale of successive generations of the product was not answered in any of the earlier work. With the aim to provide more generic intergenerational sales model which also includes the impact of information supplied to consumers, the proposed model not only offers greater flexibility with some added capabilities, but also delivers better overall performance both in terms of model fit and forecasting. Furthermore, the proposed model can incorporate the different functional form to describe the information and adoption flow. Hence, it is judicious to claim that the present model is well suited to help practitioner and firms in taking important decisions concerning towards marketing of successive generations of a product.

\section{Conclusion}

The proposed framework captures the shifting from one generation to successive generation and how they behave under two stage modeling framework. Modeling innovation diffusion as a two step process is a generalization in which the firms estimate the sales of a product from the aware consumers. Generally, the one who is not aware about the product does not go for its adoption and aware consumers may have positive or a negative thought for the product. The main focus is given to the case of two generations of a product under the assumption that awareness and adoption process have different functional forms. The movement of adopters from one generation to its successive generation has been termed as deviation; which is able to account for both 
International Journal of Mathematical, Engineering and Management Sciences

Vol. 2, No. 2, 74-84, 2017

https://dx.doi.org/10.33889/IJMEMS.2017.2.2-008

substitution and switching effects. Based on SSE, MSE, Root MSE, $R^{2}$ and Adj. $R^{2}$, it is clear that the proposed model is able to provide a good fit to considered sales data in contrast to traditional successive generation models, which assumed constant information flow with logistic distribution representing the adoption process.

\section{Acknowledgement}

The research work presented in this paper is supported by grants to the first author from DST, via DST PURSE phase II, India.

\section{Reference}

Aggrawal, D., Anand, A., Singh, O., \& Kapur, P. K. (2015). Modelling successive generations for products-in-use and number of products sold in the market. International Journal of Operational Research, 24(2), 228-244.

Anand, A., Kapur, P. K., Agarwal, M., \& Aggrawal, D. (2014a, October). Generalized innovation diffusion modeling \& weighted criteria based ranking. In Reliability, Infocom Technologies and Optimization (ICRITO) (Trends and Future Directions), 2014 3rd International Conference on (pp. 1-6). IEEE.

Anand, A., Singh, O., Agarwal, M., \& Aggarwal, R. (2014b, October). Modeling adoption process based on awareness and motivation of consumers. In Reliability, Infocom Technologies and Optimization (ICRITO) (Trends and Future Directions), 2014 3rd International Conference on (pp. 1-6). IEEE.

Bass, F. M. (1969). A new product growth for model consumer durables. Management Science, 15(5), 215227.

Bass, F. M., Krishnan, T. V., \& Jain, D. C. (1994). Why the Bass model fits without decision variables. Marketing science, 13(3), 203-223.

Bronnenberg, B. J., \& Mahajan, V. (2001). Unobserved retailer behavior in multimarket data: Joint spatial dependence in market shares and promotion variables. Marketing Science, 20(3), 284-299.

De Bruyn, A., \& Lilien, G. L. (2008). A multi-stage model of word-of-mouth influence through viral marketing. International Journal of Research in Marketing, 25(3), 151-163.

Garber, T., Goldenberg, J., Libai, B., \& Muller, E. (2004). From density to destiny: Using spatial dimension of sales data for early prediction of new product success. Marketing Science, 23(3), 419428.

Goldenberg, J., Libai, B., \& Muller, E. (2002). Riding the saddle: How cross-market communications can create a major slump in sales. Journal of Marketing, 66(2), 1-16.

Ho, T. H., Savin, S., \& Terwiesch, C. (2002). Managing demand and sales dynamics in new product diffusion under supply constraint. Management Science, 48(2), 187-206.

Islam, T. \& Meade, N. (1997). The diffusion of successive generations of a technology: A more general model. Technological Forecasting and Social Change, 56(1), 49-60.

Jain, D., Mahajan, V., \& Muller, E. (1991). Innovation diffusion in the presence of supply restrictions. Marketing Science, 10(1), 83-90.

Jiang, Z. (2010). How to give away software with successive versions. Decision Support Systems, 49(4), 430-441.

Jiang, Z., \& Jain, D. C. (2012). A generalized Norton-Bass model for multigeneration diffusion. Management Science, 58(10), 1887-1897.

Kalish, S., \& Sen, S. K. (1986). Diffusion models and the marketing mix for single products. Innovation Diffusion Models of New Product Acceptance, 87-115. 
International Journal of Mathematical, Engineering and Management Sciences

Vol. 2, No. 2, 74-84, 2017

https://dx.doi.org/10.33889/IJMEMS.2017.2.2-008

Kalish, S. (1985). A new product adoption model with price, advertising, and uncertainty. Management Science, 31(12), 1569-1585.

Kapur, P. K., Chanda, U., Tandon, A., \& Anand, S. (2010, December). Innovation diffusion of successive generations of high technology products. In Reliability, Safety and Hazard (ICRESH), 20102 nd International Conference on (pp. 505-510). IEEE.

Lilien, G. L., Rao, A. G., \& Kalish, S. (1981). Bayesian estimation and control of detailing effort in a repeat purchase diffusion environment. Management Science, 27(5), 493-506.

Mahajan, V., \& Muller, E. (1996). Timing, diffusion, and substitution of successive generations of technological innovations: The IBM mainframe case. Technological Forecasting and Social Change, 51(2), 109-132.

Mahajan, V., \& Wind, Y. (1985). Innovation diffusion models of new product acceptance: A reexamination.

Meade, N., \& Islam, T. (2006). Modelling and forecasting the diffusion of innovation-A 25-year review. International Journal of Forecasting, 22(3), 519-545.

Midgley, D. F. (1976). A simple mathematical theory of innovative behavior. Journal of Consumer Research, 31-41.

Norton, J. A., \& Bass, F. M. (1987). A diffusion theory model of adoption and substitution for successive generations of high-technology products. Management Science, 33(9), 1069-1086.

Rogers, E. M. (1962). Diffusion of Innovations. The Free Press, New York.

SAS Institute Inc. (2004). SAS/ETS user's guide version 9.1. Cary, NC: SAS Institute Inc.

Singh, O., Anand, A., Kapur, P. K., \& Aggrawal, D. (2012). Consumer behaviour-based innovation diffusion modelling using stochastic differential equation incorporating change in adoption rate. International Journal of Technology Marketing, 7(4), 346-360.

Speece, M. W., \& Maclachlan, D. L. (1995). Application of a multi-generation diffusion model to milk container technology. Technological Forecasting and Social Change, 49(3), 281-295.

Van den Bulte, C., \& Lilien, G. (2007). A two-stage model of innovation adoption with partial observability: Model development and application. Mimeo, University of Pennsylvania.

Victor, N. M., \& Ausubel, J. H. (2002). DRAMs as model organisms for study of technological evolution. Technological forecasting and Social Change, 69(3), 243-262.

Wind, Y., \& Sharma, S. (1983). An approach to repeat purchase diffusion models. In Proceedings of the American Marketing Educator's Conference. 